\title{
Prevalence, outcomes, and a risk-benefit analysis of diaphragmatic hernia admissions: An examination of the National Inpatient Sample database
}

Subroto Paul, MD, ${ }^{\text {a }}$ Farooq M. Mirza, MD, ${ }^{\mathrm{a}}$ Abu Nasar, MS, ${ }^{\mathrm{a}}$ Jeffrey L. Port, MD, ${ }^{\mathrm{a}}$ Paul C. Lee, MD, ${ }^{\mathrm{a}}$
Brendon M. Stiles, MD, ${ }^{\mathrm{a}}$ Andrew B. Nguyen, MD, ${ }^{\mathrm{a}}$ Art Sedrakyan, MD, PhD, ${ }^{\mathrm{b}}$ and Nasser K. Altorki, MD

Objective: Current practice is to repair uncomplicated diaphragmatic hernias (UDHs) to avoid complications such as obstruction or gangrene. However, practice patterns are based on limited data. We analyzed the National Inpatient Sample to compare outcomes of patients with obstructed (ODH) or gangrenous (GDH) diaphragmatic hernias and those who underwent repair of UDHs to perform a risk-benefit analysis of observation versus elective repair.

Patients and Methods: We queried the National Inpatient Sample for hospitalized patients who underwent a UDH repair as the principal procedure during their admission. To this repair group, we compared the outcomes of those patients who had a diagnosis of GDH or ODH. A risk-benefit analysis of observation versus elective repair was performed based on these data.

Results: Over a 10-year period, 193,554 admissions for the diagnosis of diaphragmatic hernia were identified. A UDH was the diagnosis in $161,777(83.6 \%)$ admissions with $38,764(24.0 \%)$ admissions for elective repair. ODH or GDH was the reason for admission in 31,127 (16.1\%) and $651(0.3 \%)$, respectively. Compared with patients who underwent elective repair, mortality was higher in patients with ODH or GDH (1\% vs $4.5 \%$; $P<.001$; and $1 \%$ vs $27.5 \% ; P<.001)$. Risk-benefit analysis suggested a small but real benefit to elective repair in patients aged 50 to 70 years or if the operative mortality is $1 \%$ or less.

Conclusions: Elective UDH repair is associated with better outcomes than admissions for ODH or GDH with a favorable risk-benefit profile than observation if the operative mortality is low. (J Thorac Cardiovasc Surg 2011;142:747-54)

Earn CME credits at

http://cme.ctsnetjournals.org
The optimal management of uncomplicated large hiatal and paraesophageal hernias is controversial. Repair of uncomplicated type II-IV hernias is often recommended to prevent the development of obstruction or gangrene. Operative repair in the setting of a complication may increase the morbidity and mortality of the procedure. However, the recommendation for repair of an uncomplicated diaphragmatic hernia (UDH) is largely based on evidence from

\footnotetext{
From the Division of Thoracic Surgery, ${ }^{\mathrm{a}}$ Department of Cardiothoracic Surgery, ${ }^{\mathrm{b}}$ Department of Public Health, New York Presbyterian Hospital System, New York, NY.

Disclosures: Authors have nothing to disclose with regard to commercial support.

Read at the 91st Annual Meeting of The American Association for Thoracic Surgery, Philadelphia, Pennsylvania, May 7-11, 2011.

Received for publication April 23, 2011; revisions received June 16, 2011; accepted for publication June 28, 2011; available ahead of print Aug 1, 2011.

Address for reprints: Subroto Paul, MD, Division of Thoracic Surgery, Department of Cardiothoracic Surgery, New York Presbyterian Hospital-Weill Cornell Medical College, New York, NY 10065 (E-mail: pas2022@med.cornell.edu). 0022-5223/\$36.00

Copyright (c) 2011 by The American Association for Thoracic Surgery doi:10.1016/j.jtcvs.2011.06.038
}

institutional case series, such as the work of Belsey and Skinner, ${ }^{1}$ or limited analyses of national databases. ${ }^{2-13}$ The countervailing view, that UDHs rarely become obstructed or gangrenous and hence do not require repair, is similarly based on institutional case series or limited examination of national data sets. ${ }^{14}$ To examine trends in the prevalence of these hernias, their rates of repair, and better characterize associated outcomes, we analyzed the $\mathrm{Na}$ tional Inpatient Sample (NIS) database, a large national database representing $20 \%$ of all inpatient admissions in the United States over a 10 -year period. The primary objective of this study was to compare the in-hospital mortality for those patients admitted for elective repair of diaphragmatic hernias (DHs)with those admitted for symptoms of obstruction or gangrene. These data were then used to construct risk-benefit profiles to compare elective repair versus observation at various age points.

\section{PATIENTS AND METHODS \\ Data Source}

The Agency for Healthcare Research and Quality, as part of the Healthcare Cost and Utilization Project (HCUP), has maintained the NIS database since 1988. The NIS is the largest all-payer inpatient care database in the United States. It contains data on more than 8 million hospital stays from approximately 1000 hospitals located in 35 states and constitutes approximately a $20 \%$ stratified sample of all hospital discharges from 


\section{Abbreviations and Acronyms \\ $\mathrm{DH}=$ diaphragmatic hernia \\ GDH = diaphragmatic hernia with gangrene \\ HCUP $=$ Healthcare Cost and Utilization Project \\ ICD- = Internal Classification of Diseases, \\ 9-CM Ninth Revision, and Clinical Modification \\ NIS = National Inpatient Sample \\ $\mathrm{ODH}=$ diaphragmatic hernia with obstruction \\ $\mathrm{UDH}=$ uncomplicated diaphragmatic hernia}

nongovernment institutions. Data contained within the NIS include patient and hospital demographics, admission and treating diagnoses, inpatient procedures, in-hospital mortality, length of hospital stay, hospital charges, as well as discharge status. The NIS data set has numerous internal quality measures and is validated by HCUP by comparison with other similar databases, National Discharge Survey, and the Medicare Provider Analysis and Review (http://www.hcup-us.ahrq.gov/nisoverview.jsp). This study was approved by the Institutional Review Board Weill Cornell Medical College and conforms to the data-use agreement for the NIS from HCUP.

\section{Data Collection}

Patient admission data were identified within the NIS based on the 2003 and 2005 Internal Classification of Diseases, Ninth Revision, and Clinical Modification (ICD-9-CM) diagnosis and procedure codes. The NIS database does not use the ICD-10 coding system. The study population consisted of patients whose principal admitting diagnosis was DH (types I-IV hiatal hernia types), whether uncomplicated (UDH: ICD-9 code 553.3), with obstruction (ODH; ICD-9 code 552.3), or with gangrene (GDH: ICD-9 code 551.3), from 1999 to 2008. Patients with congenital hernias (ICD-9-CM codes 750.6 and 756.6) were excluded.. Specific DH repair procedures were identified using the following ICD-9 CM procedures codes: open abdominal, 53.7, 53.72, and 53.75; laparoscopic approach, 53.71 or 54.21 and 54.51 in conjunction with $53.7^{15}$; and thoracotomy approach, 53.80, 53.83, and 53.84. The ICD-9-CM codes used for patient identification are summarized in Appendix Table 1. To exclude patients admitted primarily for gastrointestinal reflux and small sliding hernias, we included only admissions for which the principal diagnosis was $\mathrm{DH}$ and the principal procedure was one of the aforementioned $\mathrm{DH}$ repair codes. Any DH admission that coded other procedures (eg, antireflux procedures) as the principal procedure was excluded.

Data collected for each patient admission included the following: age at time of admission, gender, patient comorbidites, in-hospital complications, in-hospital mortality, length of stay, discharge status, and overall hospitalization charges. Patient comorbidities and in-hospital complications were identified from the patient's ICD-9-CM diagnosis codes other than the principal diagnosis code, which was DH in all cases. The NIS database allows for 15 recorded ICD-9-CM diagnosis codes per patient admission. The majority of comorbidities were recorded using the NIS comorbidity software version 3.6 format $^{16}$ (http://www.hcup-us.ahrq.gov/toolssoftware/ comorbidity/comorbidity.jsp). Specific ICD-9-CM codes used are summarized in Appendix Table 1.

\section{Study Patient Population}

During the 10-year period of this study encompassing over 381 million admissions, 193,554 patient admissions for the principal diagnosis of DH were identified. Demographics and comorbid conditions for these admissions are summarized in Table 1. Figure 1 plots the total number of admission for any DH per 1,000,000 admissions and demonstrates that the number of admissions was relatively constant during the study period at 500 per $1,000,000$ admissions (1:2000). Figure 1 also illustrates a constant proportion among admissions that carried an admitting diagnosis of UDH, ODH, or GDH. During the 10-year study period, a UDH was the diagnosis in 161,777 $(83.6 \%)$ admissions. For the purposes of analyses, we identified those hospital admissions that carried a principal diagnosis of UDH and also had a principal procedure of diaphragmatic repair as "UDH: elective repair."

\section{Study Objectives and Statistical Analysis}

The primary objective of this study was to compare the in-hospital mortality of UDH patients admitted for elective repair with those patients who were admitted with a diagnosis of ODH or GDH. Secondary objectives examined included the prevalence of the DH diagnosis, in-hospital complication rates, and length of stay.

SUDAAN (9.0.1) software program (Research Triangle Institute, Research Triangle Park, NC) was used to convert raw counts generated from the NIS database into weighted counts that were used to generate national estimates. Weighted data were used for all statistical analysis. $\chi^{2}$ Analysis for categorical data and analysis of variance for continuous data were used to test for statistical significance. All $P$ values were 2-sided with statistical significance evaluated at the .05 alpha level. Bonferroni adjustment was used when making multiple comparisons.

Logistic regression analysis was used to determine whether ODH and GDH admission status were independent risk factors for mortality. Univariate predictors of mortality with a $P$ value $\leq .05$ that were thought to be of clinical significance a priori were entered into a multivariate model. The variables considered in the model included the following: age, coronary artery disease, congestive heart failure, peripheral vascular disease, and ODH and GDH admission status. Co-linearity between independent variables was assessed using $\kappa>0.4$. No variables tested were found to be co-linear.

With the use of the mortality and morbidity end points determined, lifetime mortality risks were determined for hypothetical patients with DKs who were observed rather than immediately operated on at the time of diagnosis at various age points $(50,60,70$, and 80 years of age). Rates for conversion of UDH to symptoms (ODH/GDH) were determined from a review of the literature. On the basis of the literature ${ }^{3,7,8,11,12}$ and the pooled analysis of 5 studies by Stylopoulos, Gazelle, Rattner, ${ }^{14}$ the following rates were used: $0.69 \%, 1.16 \%, 1.93 \%$, and $3.86 \%$ per year. These rates are pooled average rates and assumed to be constant. Life expectancy was determined using 2006 life table data from The Centers for Disease Control. ${ }^{17}$ Lifetime risk for conversion from an asymptomatic to a symptomatic state was calculated using the following formula: lifetime risk $=1-(1-$ rate of conversion) ${ }^{\text {Life Expectancy } 14}$ Lifetime mortality risk was calculated as a composite value based on the ratio of time spent on the calculated admission ODH mortality during each decade of life (Table 2) using the following for-

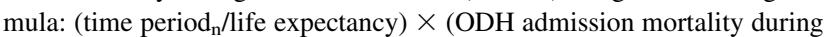
time period $\left.{ }_{n}\right)+\left(\right.$ time period $_{n+1} /$ life expectancy $) \times(\mathrm{ODH}$ admission mortality during time period $\left.\mathrm{d}_{\mathrm{n}+1}\right)+$ et cetera until life expectancy reached, where $\mathrm{n}$ represents each decade of life where ODH admission mortality was calculated. Lifetime mortality risk for asymptomatic patients was calculated by multiplying lifetime risk for conversion to a symptomatic state by lifetime mortality risk. This calculation assumes a constant rate of conversion to symptomatic DHs and no recurrences from repair requiring reoperation.

All statistical analyses were performed by using SPSS version 17.0 (SPSS, Inc, Chicago Ill) and SUDAAN (9.0.1) software program (Research Triangle Institute, Research Triangle Park, NC).

\section{RESULTS}

\section{Patient Characteristics}

Patients with either ODH or GDH were significantly older than those patients who had an elective repair of a UDH (Table 3). ODH patients had more comorbidities 
TABLE 1. Demographics of patients admitted with UDHs from 1999 to 2008

\begin{tabular}{lc}
\hline Patient demographics & UDH $(\mathbf{n}=\mathbf{1 9 3 , 5 5 4})$ \\
\hline Age (y), range & $66.0(52.0-77.0)$ \\
Gender & \\
Male & $62,568(32.3 \%)$ \\
Female & $130,986(67.7 \%)$ \\
Comorbidities & \\
CAD & $25,786(13.3 \%)$ \\
CHF & $11,544(6.0 \%)$ \\
Diabetes & $18,443(9.5 \%)$ \\
CPD & $33,435(17.3 \%)$ \\
PVD & $4,169(2.2 \%)$ \\
Race & \\
White & $121,283(62.7 \%)$ \\
African American & $8,976(4.6 \%)$ \\
Other & $48,519(25.1 \%)$ \\
Not stated & $14,777(7.6 \%)$ \\
Hospital setting & \\
Rural & $30,405(15.7 \%)$ \\
Urban (nonteaching) & $77,135(39.9 \%)$ \\
Urban (teaching) & $85,937(44.4 \%)$ \\
\hline$U D H$, Uncomplicated diaphragmatic hernia; $C A D$, coronary artery disease; $C H F$ \\
congestive heart failure; $C P D$, chronic pulmonary disease; $P V D$, peripheral vascular \\
disease.
\end{tabular}

including congestive heart failure, coronary artery disease, and peripheral vascular disease than those undergoing UDH repair (Table 3). Patients admitted with GDH also had a similarly higher rate of comorbidities (Table 3 ). However, owing to the small number of GDH admissions, only the rate of congestive heart failure was statistically significant. The majority of DH admissions were in urban centers. However, in rural centers admissions for ODH exceeded admissions for UDH with elective repair. Admissions for the elective repair of UDH were more frequent in urban teaching hospitals than those for ODH and GDH (Table 3).

\section{In-Hospital Mortality and Morbidity}

Analysis of hospital outcomes of patient admissions for UDH with elective repair versus ODH versus GDH is shown

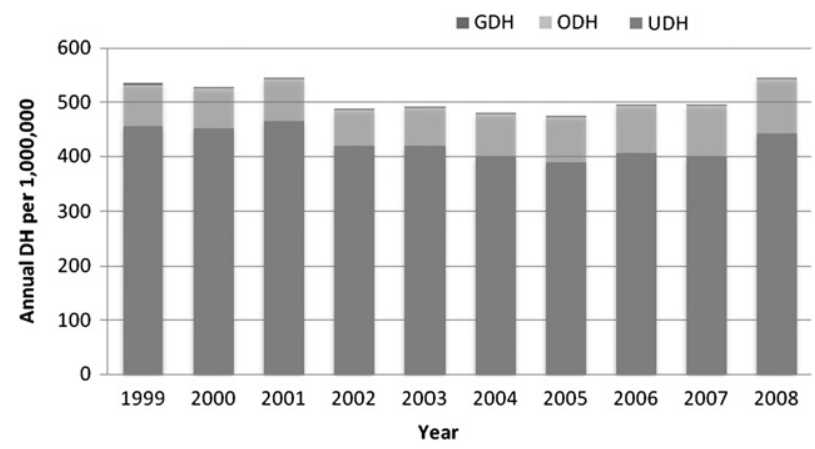

FIGURE 1. Diaphragmatic hernia $(D H)$ patients per $1,000,000$ admitted in US hospital admissions from 1999 to 2008. GDH, Diaphragmatic hernia with gangrene; $O D H$, diaphragmatic hernia with obstruction; $U D H$, uncomplicated diaphragmatic hernia.
TABLE 2. Mortality outcomes of patients with ODH and GDH compared with those of patients with UDH undergoing elective repair from 1999 to 2008 by age group

\begin{tabular}{lccc}
\hline $\begin{array}{c}\text { Age } \\
\text { group }\end{array}$ & $\begin{array}{c}\text { UDH: Elective } \\
\text { repair (deaths/total } \\
\text { n per age group) }\end{array}$ & $\begin{array}{c}\text { ODH } \\
\text { (deaths/total n } \\
\text { per age group) }\end{array}$ & $\begin{array}{c}\text { GDH } \\
\text { (deaths/total } \\
\text { n per age group) }\end{array}$ \\
\hline$<50$ y & $0.13 \%(12 / 8952)$ & $1.2 \%(49 / 4085)$ & $5.6 \%(5 / 90)$ \\
$50-59$ y & $0.39 \%(24 / 6193)$ & $0.86 \%(31 / 3615)$ & $22.9 \%(16 / 70)$ \\
$60-69$ y & $0.27 \%(58 / 8891)$ & $2.0 \%(107 / 5398)$ & $13.5 \%(10 / 74)$ \\
$70-79$ y & $1.16 \%(110 / 9483)$ & $3.3 \%(271 / 8181)$ & $32.8 \%(41 / 127)$ \\
$\geq 80$ y & $3.9 \%(202 / 5224)$ & $9.7 \%(955 / 9842)$ & $36.8 \%(107 / 291)$ \\
\hline$O D H$, Obstructed diaphragmatic hernia; $G D H$, gangrenous fiaphragmatic hernia; \\
$U D H$, uncomplicated diaphragmatic hernia.
\end{tabular}

in Table 4. Hospital mortality was significantly higher in patients admitted with ODH or GDH compared with those patients who had elective repair of UDH $(4.5 \%$ vs $1 \%$; $P<.001$; and $27.5 \%$ vs $1 \% ; P<.001$, respectively). Hospital mortality was age dependent for all 3 groups (Table 2). Patient admissions for ODH and GDH were associated with complications in $23.2 \%$ and $57.1 \%$, respectively, compared with only $10.4 \%$ of admissions for elective UDH repair $(P<.001$, Table 4$)$. Specific complications that occurred with a greater frequency in the ODH and GDH groups than in the UDH elective repair group included pneumonia and sepsis (Table 4). Patients admitted for ODH or GDH also more frequently needed mechanical ventilation than those admitted for elective repair (Table 4).

The length of stay of admissions for ODH and GDH was significantly longer that for admissions for elective repair of UDH (Table 4). ODH and GDH patients were also more likely to be transferred to an intermediate care facility than discharged to home (Table 4).

\section{Risk Factors for In-Hospital Mortality}

To ascertain whether ODH or GDH admission status was an independent predictor of hospital mortality, we used logistic regression analysis to test the effect of several factors including ODH and GDH admission status on mortality (Table 5). Six univariate predictors of mortality were identified: age, the presence of coronary artery disease, congestive heart failure, peripheral vascular disease, and ODH and GDH admission status (Table 5). These univariate predictors with $P$ values $\leq .05$ were entered into a multivariate model. This model identified ODH and GDH admission status $(P=.001)$ along with age $(P<.001)$ and the presence of congestive heart failure $(P<.001)$ as independent predictors of mortality (Table 6).

\section{Calculated Lifetime Mortality Risk From Observation}

Lifetime mortality risk from $\mathrm{DH}$ observation was determined for theoretical patients aged $50,60,70$, or 80 
TABLE 3. Demographics of patients admitted with UDH: Elective repair versus ODH versus GDH from 1999 to 2008

\begin{tabular}{|c|c|c|c|c|c|}
\hline \multirow{3}{*}{$\begin{array}{c}\text { Patient } \\
\text { demographics }\end{array}$} & \multicolumn{5}{|c|}{ DH $(n=70,542)$} \\
\hline & Group 1 & Group 2 & Group 1 vs group 2 & Group 3 & Group 1 vs group 3 \\
\hline & $\begin{array}{l}\text { UDH: Elective repair } \\
\quad(n=38,764)\end{array}$ & $\begin{array}{c}\text { ODH } \\
(\mathbf{n}=\mathbf{3 1 , 1 2 7})\end{array}$ & $\begin{array}{c}P \\
\text { value }\end{array}$ & $\begin{array}{c}\text { GDH } \\
(n=651)\end{array}$ & $\begin{array}{c}P \\
\text { value }\end{array}$ \\
\hline Age $(y)$, range & $65.0(52.0-75.0)$ & $73.0(60.0-82.0)$ & $P<.001$ & $77.0(62.0-84.0)$ & $P<.001$ \\
\hline \multicolumn{6}{|l|}{ Gender } \\
\hline Male & $13,360(34.5 \%)$ & $11,317(46.4 \%)$ & $P=.020$ & $237(36.4 \%)$ & $P=.641$ \\
\hline Female & $25,404(65.5 \%)$ & $19,810(63.6 \%)$ & & $414(63.6 \%)$ & \\
\hline \multicolumn{6}{|l|}{ Comorbidities } \\
\hline $\mathrm{CAD}$ & $3,893(10.0 \%)$ & $4,059(13 \%)$ & $P<.001$ & $60(9.2 \%)$ & $P=.716$ \\
\hline CHF & $1,742(4.5 \%)$ & $3,114(10.0 \%)$ & $P<.001$ & $87(13.3 \%)$ & $P=.004$ \\
\hline Diabetes & $2,640(6.8 \%)$ & $2,883(9.3 \%)$ & $P<.001$ & $51(7.8 \%)$ & $P=.670$ \\
\hline CPD & $6,879(17.7 \%)$ & $5,357(17.2 \%)$ & $P=.406$ & $87(13.4 \%)$ & $P=.139$ \\
\hline PVD & $597(1.5 \%)$ & $791(2.5 \%)$ & $P<.001$ & $27(4.1 \%)$ & $P=.163$ \\
\hline \multicolumn{6}{|l|}{ Race } \\
\hline White & $24,905(62.4 \%)$ & $20,158(64.8 \%)$ & $P=.781$ & $456(70.0 \%)$ & $P=.227$ \\
\hline African American & $1,093(2.8 \%)$ & $918(2.9 \%)$ & & $23(3.5 \%)$ & \\
\hline Other & $9,983(25.8 \%)$ & $7,928(25.5 \%)$ & & $121(18.6 \%)$ & \\
\hline Not stated & $2,783(7.2 \%)$ & $2,123(6.8 \%)$ & & $51(7.8 \%)$ & \\
\hline \multicolumn{6}{|l|}{ Hospital setting } \\
\hline Rural & $4,196(10.8 \%)$ & $4,421(14.2 \%)$ & $P<.001$ & $59(9.0 \%)$ & $P=.043$ \\
\hline Urban (nonteaching) & $12,631(32.6 \%)$ & $13,227(42.5 \%)$ & & $284(43.6 \%)$ & \\
\hline Urban (teaching) & $21,938(56.6 \%)$ & $13,469(43.3 \%)$ & & $309(47.4 \%)$ & \\
\hline
\end{tabular}

$P$ values < .05 are in bold. $U D H$, Uncomplicated diaphragmatic hernia; $O D H$, obstructed diaphragmatic hernia; $G D H$, gangrenous diaphragmatic hernia; $D H$, diaphragmatic hernia; $C A D$, coronary artery disease; $C H F$, congestive heart failure; $C P D$, chronic pulmonary disease; $P V D$, peripheral vascular disease.

(Table 7). Inasmuch as the rate of conversion from UDH to $\mathrm{ODH}$ or GDH is not known, conversion rates ranging from $0.69 \%$ to $3.96 \%$ per year were used based on the analysis of Stylopoulos, Gazelle, and Rattner, ${ }^{14}$ which are assumed to be constant hazard rates. As shown in Table 7, immediate elective repair is associated with a favorable risk-benefit profile for both 50- and 60-year-old patients at all conversion rates. However, the benefit for immediate repair is lost in an 80-year-old patient as well as in a 70-year-old patient unless the rate of conversion to obstruction or gangrene $(\mathrm{ODH}$ or $\mathrm{GDH})$ is approximately $2 \%$ per year or greater.

TABLE 4. Outcomes of patients with ODH and GDH compared with those of patients with UDH undergoing elective repair from 1999 to 2008

\begin{tabular}{|c|c|c|c|c|c|}
\hline & \multicolumn{5}{|c|}{ UDH undergoing repair vs ODH and GDH } \\
\hline & Group 1 & Group 2 & Group 1 vs group 2 & Group 3 & Group 1 vs group 3 \\
\hline & $\begin{array}{l}\text { UDH: Elective repair } \\
\quad(n=38,764)\end{array}$ & $\begin{array}{c}\text { ODH } \\
(n=31,127)\end{array}$ & $\begin{array}{c}P \\
\text { value }\end{array}$ & $\begin{array}{c}\text { GDH } \\
(n=651)\end{array}$ & $\begin{array}{c}P \\
\text { value }\end{array}$ \\
\hline \multicolumn{6}{|l|}{ In-hospital outcomes } \\
\hline Mortality & $406(1.0 \%)$ & $1,413(4.5 \%)$ & $P<.001$ & $179(27.5 \%)$ & $P<.001$ \\
\hline Length of stay (d), range & $4.0(2.0-7.0)$ & $7.0(4.0-1.0)$ & $P<.001$ & $12.0(7.0-20.0)$ & $P<.001$ \\
\hline \multicolumn{6}{|l|}{ Morbidity } \\
\hline Pneumonia & $1,199(3.1 \%)$ & $1,870(6.0 \%)$ & $P<.001$ & $75(11.5 \%)$ & $P<.001$ \\
\hline Mechanical ventilation & $1,382(3.6 \%)$ & $3,021(9.7 \%)$ & $P<.001$ & $269(41.3 \%)$ & $P<.001$ \\
\hline Deep venous thrombosis & $198(0.5 \%)$ & $260(0.8 \%)$ & $P=.021$ & $0(0 \%)$ & $P=.349$ \\
\hline Pulmonary embolism & $211(0.5 \%)$ & $293(0.9 \%)$ & $P=.007$ & $7(1.1 \%)$ & $P=.601$ \\
\hline Myocardial infarction & $528(1.4 \%)$ & $742(2.4 \%)$ & $P<.001$ & $18(2.8 \%)$ & $P=.349$ \\
\hline Sepsis & $221(0.6 \%)$ & $714(2.3 \%)$ & $P<.001$ & $100(15.4 \%)$ & $P<.001$ \\
\hline Urinary tract infection & $1088(2.8 \%)$ & $2326(7.5 \%)$ & $P<.001$ & $62(9.5 \%)$ & $P=.009$ \\
\hline \multicolumn{6}{|l|}{ Discharge status } \\
\hline Routine & $35,017(90.3 \%)$ & $22,763(73.1 \%)$ & $P<.001$ & $230(35.3 \%)$ & $P<.001$ \\
\hline Intermediate care & $3,297(8.5 \%)$ & $6,849(22.0 \%)$ & & $243(37.3 \%)$ & \\
\hline Died in hospital & $406(1.0 \%)$ & $1,413(4.5 \%)$ & & $179(27.5 \%)$ & \\
\hline Not stated/missing & $44(0.1 \%)$ & $101(0.3 \%)$ & & $0(0.0 \%)$ & \\
\hline
\end{tabular}

$P$ values $<.05$ are in bold. $O D H$, Obstructed diaphragmatic hernia; $G D H$, gangrenous diaphragmatic hernia; $U D H$, uncomplicated diaphragmatic hernia. 
TABLE 5. Univariate predictors of mortality

\begin{tabular}{|c|c|c|}
\hline \multirow[b]{2}{*}{ Variable } & \multicolumn{2}{|c|}{ DH $(N=70,542)$} \\
\hline & OR $(95 \%$ CI $)$ & $P$ value \\
\hline Age (continuous) & $1.08(1.07-1.10)$ & $P<.001$ \\
\hline \multicolumn{3}{|l|}{ Gender } \\
\hline Male & (Ref): 1.00 & $P=.233$ \\
\hline Female & $1.14(0.92-1.40)$ & \\
\hline \multicolumn{3}{|l|}{ Comorbidities } \\
\hline $\mathrm{CAD}$ & $1.34(1.01-1.78)$ & $P=\mathbf{. 0 4 3}$ \\
\hline CHF & $5.98(4.77-4.49)$ & $P<.001$ \\
\hline Diabetes & $1.02(0.71-1.47)$ & $P=.902$ \\
\hline CPD & $1.21(0.95-1.55)$ & $P=.126$ \\
\hline PVD & $2.16(1.30-3.58)$ & $P=\mathbf{0 0 3}$ \\
\hline \multicolumn{3}{|l|}{ Race } \\
\hline White & (Ref): 1.00 & \\
\hline African American & $0.73(0.37-1.43)$ & $P=.354$ \\
\hline Other & $0.92(0.73-1.17)$ & $P=.498$ \\
\hline Not stated & $1.18(0.82-1.71)$ & $P=.365$ \\
\hline \multicolumn{3}{|l|}{ Hospital setting } \\
\hline Rural & (Ref): 1.00 & \\
\hline Urban (nonteaching) & $1.10(0.80-1.51)$ & $P=.567$ \\
\hline Urban (teaching) & $0.83(0.61-1.14)$ & $P=.257$ \\
\hline \multicolumn{3}{|l|}{ Admission diagnosis } \\
\hline UDH: Elective repair & (Ref): 1.00 & \\
\hline $\mathrm{ODH}$ & $4.49(3.51-5.74)$ & $P<.001$ \\
\hline GDH & $35.69(23.07-55.20)$ & $P<.001$ \\
\hline
\end{tabular}

$D H$, Diaphragmatic hernia; $O R$, odds ratio; $C I$, confidence intervals; $R e f$, reference value; $C A D$, coronary artery disease; $C H F$, congestive heart failure; $C P D$, chronic pulmonary disease; $P V D$, peripheral vascular disease; $U D H$, uncomplicated diaphragmatic hernia; $O D H$, obstructed diaphragmatic hernia; $G D H$, gangrenous diaphragmatic hernia.

\section{DISCUSSION}

The principal finding of our analysis of 10 years of NIS data is that admission for nonelective repair of DHs is associated with a significant increase in hospital mortality and morbidity when compared with elective repair. As expected, the mortality and morbidity are greatest for those admitted with gangrene but not insignificant for those admitted for obstructive symptoms. Furthermore, lifetime risk analysis favors elective repair of uncomplicated DHs for individuals 50 to 60 years of age. The risk-benefit profile from elective repair is diminished in older patients unless the conversion rate from a UDH to an ODH or GDH is at least $2 \%$ per year or higher. Controversy still exists as to whether UDHs should be repaired. In a decision analysis using 1997 NIS data, Stylopoulos, Gazelle, and Rattner ${ }^{14}$ favored observation over elective repair. In their analysis, a $1.16 \%$ per year conversion rate was used with a $5.4 \%$ operative mortality for patients operated on with obstructive symptoms and a $1.4 \%$ operative mortality rate for elective repair. ${ }^{14}$ However, we show, as others have, that hospital mortality for both elective repair and admissions for obstruction or gangrene is age dependent. ${ }^{2,18}$ Hence, lifetime risk from observation should be calculated on an age-dependent basis and compared with the operative mortality at the age at elective repair.
TABLE 6. Multivariate predictors of mortality

\begin{tabular}{lcc}
\hline \multirow{2}{*}{ Variable } & \multicolumn{2}{c}{ DH $(\mathbf{N}=\mathbf{7 0 , 5 4 2})$} \\
\cline { 2 - 3 } Age (continuous) & OR $(\mathbf{9 5} \% \mathbf{C I})$ & $\boldsymbol{P}$ value \\
Comorbidities & $1.06(1.05-1.08)$ & $\boldsymbol{P}<. \mathbf{0 0 1}$ \\
CAD & $0.79(0.58-1.08)$ & $P=.137$ \\
CHF & $2.93(2.27-3.79)$ & $\boldsymbol{P}<. \mathbf{0 0 1}$ \\
PVD & $1.44(0.85-2.44)$ & $P=.175$ \\
Admission diagnosis & & \\
UDH: Elective repair & (Ref): 1.00 & \\
ODH & $2.77(2.14-3.60)$ & $\boldsymbol{P}<. \mathbf{0 0 1}$ \\
GDH & $22.34(13.42-37.18)$ & $\boldsymbol{P}<. \mathbf{0 0 1}$ \\
\hline
\end{tabular}

$D H$, Diaphragmatic hernia; $O R$, odds ratio; $C I$, confidence intervals; $C A D$, coronary artery disease; $C H F$, congestive heart failure; $P V D$, peripheral vascular disease; Ref reference value; $U D H$, uncomplicated diaphragmatic hernia; $O D H$, obstructed diaphragmatic hernia; $G D H$, gangrenous diaphragmatic hernia.

The crucial issue becomes the rate of conversion from a UDH to an ODH or GDH. This is not known. A review of the literature reports values ranging from $0.7 \%$ per year to $7 \%$ per year. ${ }^{3,7,8,11,12,14}$ Stylopoulos, Gazelle, and Rattner ${ }^{14}$ calculated an average of $1.16 \%$ per year based on 5 studies with a range of $0.69 \%$ to $1.96 \%$ per year, which were the basis of the values used in our lifetime risk analysis., ${ }^{3,7,8,11,12,14}$ This rate is assumed to be constant in our analysis but may also be age dependent, increasing with age as hiatal tissues may weaken with advancing age. ${ }^{19}$ Hence, it is not unreasonable to suggest that higher rates of conversion may occur in elderly patients, thereby favoring elective DH repair even in older patients. Furthermore, it is important to recognize that the risk-benefit calculation is heavily influenced by hospital mortality. Hospital mortality rates for elective repair in patients over 70 years of age equal to or less than $1 \%$ would be associated with the most favorable risk-benefit profile.

We also found that DH is a relatively common problem, accounting for roughly 1 in every 2000 hospital admissions, the majority of which involve white female patients. Of these admissions, $16 \%$ were for obstructive symptoms. Clinical presentation with gangrene appears to be a rare event. Our study also shows that patients admitted for obstructive symptoms are most often admitted to rural hospital centers. This may suggest that many of these patients either did not receive a diagnosis or were not offered elective repair in this setting. Further analysis of other large national databases is required to confirm these findings and, if confirmed, may raise new questions of access to surgical intervention in these areas.

We recognize that there are several limitations to our analysis. First, this analysis is dependent on the ICD-9$\mathrm{CM}$ diagnosis codes used by hospitals and recorded in the NIS database. Although we selected only patient admissions with a primary diagnosis code for DH and primary procedure code for DH repair to avoid selecting patients with small hiatal hernias undergoing fundoplication, it is 
TABLE 7. Lifetime risk analysis: Elective repair versus observation

\begin{tabular}{|c|c|c|c|c|c|c|}
\hline Age & $\begin{array}{c}\text { UDH: Elective } \\
\text { repair mortality } \\
(\%) \\
\end{array}$ & $\begin{array}{c}\text { Life } \\
\text { expectancy }(y)\end{array}$ & $\begin{array}{l}\text { Rate of development } \\
\text { of ODH/GDH }(\% / y)\end{array}$ & $\begin{array}{c}\text { Lifetime risk } \\
\text { ODH/GDH } \\
\text { development }(\%) \\
\end{array}$ & $\begin{array}{c}\text { Adjusted mortality } \\
\text { rate for ODH admission } \\
\text { over life span (\%) } \\
\end{array}$ & $\begin{array}{c}\text { Lifetime mortality } \\
\text { risk from observation }(\%)\end{array}$ \\
\hline \multirow[t]{4}{*}{$50 \mathrm{y}$} & 0.39 & 30.7 & 0.69 & 19.15 & 2.22 & 0.43 \\
\hline & & & 1.16 & 30.11 & 2.22 & 0.70 \\
\hline & & & 1.93 & 45.02 & 2.22 & 1.00 \\
\hline & & & 3.86 & 70.14 & 2.22 & 1.56 \\
\hline \multirow[t]{4}{*}{$60 \mathrm{y}$} & 0.27 & 22.4 & 0.69 & 14.37 & 2.53 & 0.36 \\
\hline & & & 1.16 & 23.00 & 2.53 & 0.57 \\
\hline & & & 1.93 & 35.37 & 2.53 & 0.89 \\
\hline & & & 3.86 & 58.60 & 2.53 & 1.48 \\
\hline \multirow[t]{4}{*}{$70 \mathrm{y}$} & 1.16 & 14.9 & 0.69 & 9.80 & 5.40 & 0.53 \\
\hline & & & 1.16 & 15.96 & 5.40 & 0.86 \\
\hline & & & 1.93 & 25.20 & 5.40 & 1.36 \\
\hline & & & 3.86 & 44.37 & 5.40 & 2.40 \\
\hline \multirow[t]{4}{*}{$80 \mathrm{y}$} & 3.9 & 8.7 & 0.69 & 5.85 & 9.70 & 0.57 \\
\hline & & & 1.16 & 9.65 & 9.70 & 0.94 \\
\hline & & & 1.93 & 15.60 & 9.70 & 1.51 \\
\hline & & & 3.86 & 29.00 & 9.70 & 2.81 \\
\hline
\end{tabular}

$U D H$, Uncomplicated diaphragmatic hernia; $O D H$, obstructed diaphragmatic hernia; $G D H$, gangrenous diaphragmatic hernia.

neither possible nor feasible to authenticate this. However, HCUP does externally validate the NIS data with other databases and hence the probability of this is negligible. It is also doubtful that small hernias would cause obstructive or gangrenous symptoms. Also as noted, the exact rate of conversion to an ODH or GDH state is not known. We provide only estimates based on the literature. Determining this rate is an elusive goal inasmuch as most national databases do not record patient identifiers for benign conditions, unlike databases for malignant disease, and hence patients cannot be followed up longitudinally. Last, our risk-benefit analysis only accounts for age and not the presence of severe comorbidities. Actuarial analysis is limited to the life expectancy for the population and not those with severe comorbidities limiting life span. The presence of severe patient comorbidities along with advanced age clearly play into any discussion of elective hernia repair.

In conclusion, our analysis of the NIS demonstrates elective $\mathrm{DH}$ repair to be associated with better outcomes than admissions for ODH or GDH with a favorable risk-benefit profile than observation if the operative mortality is low. Additional studies are needed to confirm these findings.

\section{References}

1. Skinner DB, Belsey RH. Surgical management of esophageal reflux and hiatus hernia. Long-term results with 1,030 patients. J Thorac Cardiovasc Surg. 1967;53:33-54.

2. Poulose BK, Gosen C, Marks JM, Khaitan L, Rosen MJ, Onders RP, et al. Inpatient mortality analysis of paraesophageal hernia repair in octogenarians. J Gastrointest Surg. 2008;12:1888-92.

3. Allen MS, Trastek VF, Deschamps C, Pairolero PC. Intrathoracic stomach: presentation and results of operation. J Thorac Cardiovasc Surg. 1993;105:253-8; discussion 258-9.

4. Geha AS, Massad MG, Snow NJ, Baue AE. A 32-year experience in 100 patients with giant paraesophageal hernia: the case for abdominal approach and selective antireflux repair. Surgery. 2000;128:623-30.
5. Haas O, Rat P, Christophe M, Friedman S, Favre JP. Surgical results of intrathoracic gastric volvulus complicating hiatal hernia. Br J Surg. 1990;77:1379-81.

6. Nissen R, Rossetti M. Surgery of hiatal and other diaphragmatic hernias. J Int Coll Surg. 1965;43:663-74.

7. Pitcher DE, Curet MJ, Martin DT, Vogt DM, Mason J, Zucker KA. Successful laparoscopic repair of paraesophageal hernia. Arch Surg. 1995;130:590-6.

8. Gantert WA, Patti MG, Arcerito M, Feo C, Stewart L, DePinto M, et al. Laparoscopic repair of paraesophageal hiatal hernias. J Am Coll Surg. 1998;186:428-32; discussion 432-3.

9. Maziak DE, Todd TR, Pearson FG. Massive hiatus hernia: evaluation and surgical management. J Thorac Cardiovasc Surg. 1998;115:53-60; discussion 61-2.

10. Roviralta E. The natural evolution of hiatal hernias. Arch Dis Child. 1964;39: 143-8.

11. Carlson MA, Condon RE, Ludwig KA, Schulte WJ. Management of intrathoracic stomach with polypropylene mesh prosthesis reinforced transabdominal hiatus hernia repair. J Am Coll Surg. 1998;187:227-30.

12. Hallissey MT, Ratliff DA, Temple JG. Paraoesophageal hiatus hernia: surgery for all ages. Ann R Coll Surg Engl. 1992;74:23-5.

13. Altorki NK, Yankelevitz D, Skinner DB. Massive hiatal hernias: the anatomic basis of repair. J Thorac Cardiovasc Surg. 1998;115:828-35.

14. Stylopoulos N, Gazelle GS, Rattner DW. Paraesophageal hernias: operation or observation? Ann Surg. 2002;236:492-500; discussion 500-1.

15. Finlayson SR, Birkmeyer JD, Laycock WS. Trends in surgery for gastroesophageal reflux disease: the effect of laparoscopic surgery on utilization. Surgery. 2003; 133:147-53.

16. Elixhauser A, Steiner C, Harris DR, Coffey RM. Comorbidity measures for use with administrative data. Med Care. 1998;36:8-27.

17. Arias E. United States life tables, 2006. Natl Vital Stat Rep. 2006;58:1-40.

18. Polomsky M, Hu R, Sepesi B, O'Connor M, Qui X, Raymond DP, et al. A population-based analysis of emergent vs. elective hospital admissions for an intrathoracic stomach. Surg Endosc. 2010;24:1250-5.

19. Gangopadhyay N, Perrone JM, Soper NJ, Matthews BD, Eagon JC, Klingensmith ME, et al. Outcomes of laparoscopic paraesophageal hernia repair in elderly and high-risk patients. Surgery. 2006;140:491-8; discussion 498-9.

\section{Discussion}

Dr Michael A. Maddaus (Minneapolis, Minn). I have no disclosures. I appreciate your sending these slides and manuscript to me in advance. This is an interesting paper that uses a good source for the data acquisition, and although intuitive, I found 
the data on admissions to be very telling about how patients fare with elective repairs versus emergency repairs. However, I am concerned that the study is not designed to demonstrate causality because I do not believe you can conclude, based on the delivered data, that elective repair prevents future complications. The reason is that the analysis about the risk of complications developing over time is problematic. Although through no fault of your own, the original data about progression to a complication are flawed and of poor quality. Why is that? Well, the best way to determine what is best for patients with a UDH would be a randomized surgical trial versus waiting, and this does not exist and will likely never exist. Otherwise, matched cohorts would be the second best way, but that does not exist either. Hence, the analysis of risk for development of a complication is faulty inasmuch as it has never been determined based on comparable patient populations. It is very simple. Most patients with a large hiatal hernia undergo surgery, so a few patients are left without a repair. There are no comparable populations anywhere to be found. With that in mind, I believe that your statistical analysis of lifetime risk assessment is definitely suggestive, at best, but far from conclusive. At this time it does not warrant a specific practice change, as you stated in your last sentences of the manuscript: "In conclusion, our analysis of the NIS demonstrates elective DH repair to be associated with better outcomes than admissions for ODH or GDH with a favorable risk-benefit profile than observation if the operative mortality is low. Additional studies are needed to confirm these findings." Do you have any comments on my observations and this perspective at this point? I strongly commend you for your effort to try to provide an answer for this perplexing situation that we often see in practice.

Dr Paul. Thank you for your comments, Dr Maddaus. I agree with many of the points that you brought up. There will never be a randomized trial to assess observation versus elective repair of these hernias, and most of the studies, including our analysis, are limited by the fact that we do not know what the rate of conversion to symptoms is. Our model makes many assumptions. One is that once the hernia has been repaired, it does not recur. It also makes the assumption that the rate of occurrence is constant, and that may not be the case. It may be that if the patient is young, the rate of occurrence of symptoms to a conversion to a gangrenous state is $1 \%$ per year, but if the patient is 70 it may be $2 \%, 4 \%$, or $5 \%$. There may be age-related degeneration of the hiatal tissue. These are things that we cannot account for because we just do not know the data. I would agree with you also that our analysis suggests a favorable risk-benefit profile to elective repair. The data are suggestive but maybe not a practice pattern changer. However, I do not see how we are going to get any more additional information because a randomized trial will not be done. You could do a metaanalysis of the literature, but that is also flawed because it is going to be done over decades of time. I agree with you that the data are suggestive, but it is what we have for now.

Dr Antoon E. M. R. Lerut (Leuven, Belgium). Thank you for this presentation. These are indeed interesting data. However, it is always tricky to propose a major operation to a patient who is completely asymptomatic, certainly if the benefit is really very, very small. Indeed, the surgery in itself will create quite a bit of morbidity from which the patient may die after the intervention or be handicapped for the rest of his or her life. I do not know whether you have looked into that.

Dr Paul. I appreciate your comments, Dr Lerut. The NIS has only short-term data of in-hospital mortality. Long-term followup is lacking, so we really do not know how these patients do. The database offers no information, for example, on the 50-yearold whose DH is fixed but who cannot eat because he has dysphagia. We can only comment on the mortality based on this database.

Dr Shaf Keshavjee (Toronto, Ontario, Canada). Along those lines, the NIS database is an administrative database, and I think the next presentation is also going to highlight some of those limitations of using administrative data. Do you think something like the Society of Thoracic Surgeons database might help us to answer questions like this?

Dr Paul. Well, the Society of Thoracic Surgeons database has more granularity than the NIS in terms of data; however, it is also limited by the fact that it has only short-term outcomes. It tells you about immediate postoperative complications and mortality, but it does not give you long-term follow-up on the patients. I know that the Society of Thoracic Surgeons is working on incorporating long-term data into the database in the future.

Dr Keshavjee. It will also provide the index set of patients so that someone who is interested in looking at the question at least can identify the patients and pull groups together to specifically ask the question in terms of the follow-up.

Dr Varun Puri (St Louis, Mo). I greatly enjoyed your presentation. I have one very simple question for you. What exactly is the definition of a DH in the NIS?

Dr Paul. The NIS codes hiatal hernia types I, II, III, and IV as DHs. We tried to exclude all the patients who had primarily reflux and a small hiatal hernia. We excluded patients in whom the primary or principal diagnosis was reflux. We excluded patients in whom the primary repair diagnosis or principal procedure diagnosis was not DH. I am sure there is going to be some washout of the data, but the impact is likely small. 
APPENDIX TABLE 1. ICD-9-CM codes used for procedures type, demographics, and in-hospital complications of patients with UDH undergoing repair from 1999 to 2008

\begin{tabular}{|c|c|}
\hline \multicolumn{2}{|c|}{ UDH $(n=38,766 ;$ ICD-9-CM code $)$} \\
\hline DH type & ICD-9-CM code \\
\hline $\mathrm{UDH}(\mathrm{n}=161,777)$ & 553.3 \\
\hline $\mathrm{ODH}(\mathrm{n}=31,127)$ & 552.3 \\
\hline $\mathrm{GDH}(\mathrm{n}=651)$ & 551.3 \\
\hline \multicolumn{2}{|l|}{ Procedure codes } \\
\hline Repair & $\begin{array}{l}53.7,53.72,53.75,53.71,54.21+54.51+53.7 \\
\quad 53.80,53.83,53.84\end{array}$ \\
\hline \multicolumn{2}{|l|}{ Comorbidities } \\
\hline CAD & $414.00,414.01,414.9,412$ \\
\hline $\mathrm{CHF}^{*}$ & $398.91,428.0-428.9$ \\
\hline Diabetes* & $\begin{array}{l}250.00-250.33,648.00-648.04,249.00- \\
\quad 249.31,250.40-250.93 \\
7751,249.40-249.91\end{array}$ \\
\hline CPD* & $\begin{array}{l}490-492.8,493.00-493.92,494-494.1,495.0- \\
505,5064\end{array}$ \\
\hline PVD* & $\begin{array}{l}\text { 440.0-440.9, 441.00- 441.9, 442.0-442.9, } \\
\text { 443.1-443.9, 444.21-444.22, 4471, 449, } \\
5571,5579\end{array}$ \\
\hline \multicolumn{2}{|l|}{ Morbidity } \\
\hline Pneumonia & $486,481,482.8,482.3$ \\
\hline Mechanical ventilation & $96.70,96.71,96.72$ \\
\hline DVT & $\begin{array}{l}451.1,451.2,451.81,451.9,453.2,453.8, \\
\quad 453.9\end{array}$ \\
\hline PE & $415.1,415.11,415.12,415.19$ \\
\hline MI & $410-10.9,411.81,413-413.9$ \\
\hline Sepsis & $995.91,038,995.92,999.3$ \\
\hline UTI & $599.0,590.9$ \\
\hline \multicolumn{2}{|c|}{$\begin{array}{l}U D H \text {, Uncomplicated diaphragmatic hernia; } O D H \text {, obstructed diaphragmatic hernia; } \\
G D H \text {, gangrenous diaphragmatic hernia; } C A D \text {, coronary artery disease; } C H F \text {, conges- } \\
\text { tive heart failure; } C P D \text {, chronic pulmonary disease; } P V D \text {, peripheral vascular disease; } \\
D V T \text {, deep vein thrombosis; } P E \text {, pulmonary embolism; } M I \text {, myocardial infarction; } \\
U T I \text {, urinary tract infection. *ICD-9-CM used from National Inpatient Sample co- } \\
\text { morbidity software, version-3.6 format. }\end{array}$} \\
\hline
\end{tabular}

